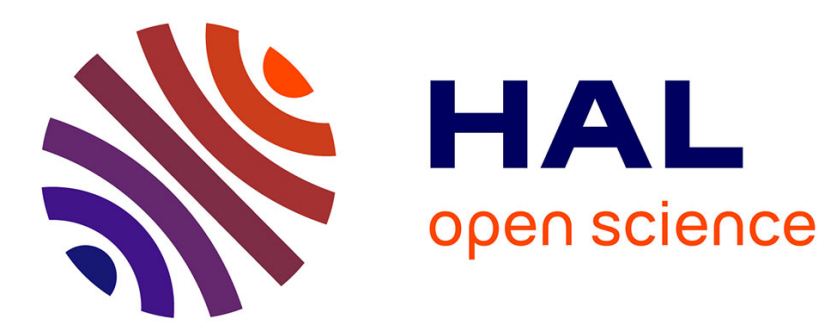

\title{
Bioinspired, Cholesteric Liquid-Crystal Reflectors with Time-Controlled Coexisting Chiral and Achiral Structures
}

Cécilia Boyon, Vanessa Soldan, Michel Mitov

\section{- To cite this version:}

Cécilia Boyon, Vanessa Soldan, Michel Mitov. Bioinspired, Cholesteric Liquid-Crystal Reflectors with Time-Controlled Coexisting Chiral and Achiral Structures. ACS Applied Materials \& Interfaces, 2021, 13 (25), pp.30118-30126. 10.1021/acsami.1c08218 . hal-03281412

\section{HAL Id: hal-03281412 \\ https://hal.science/hal-03281412}

Submitted on 8 Jul 2021

HAL is a multi-disciplinary open access archive for the deposit and dissemination of scientific research documents, whether they are published or not. The documents may come from teaching and research institutions in France or abroad, or from public or private research centers.
L'archive ouverte pluridisciplinaire HAL, est destinée au dépôt et à la diffusion de documents scientifiques de niveau recherche, publiés ou non, émanant des établissements d'enseignement et de recherche français ou étrangers, des laboratoires publics ou privés. 


\title{
Bioinspired, Cholesteric Liquid Crystal Reflectors with
}

\section{Time-Controlled, Coexisting Chiral and Achiral Structures}

Cécilia Boyon, ${ }^{1}$ Vanessa Soldan, ${ }^{2}$ and Michel Mitov ${ }^{*}, 1$

${ }^{1}$ Centre d'Elaboration de Matériaux et d'Etudes Structurales, CEMES, CNRS, Toulouse, France.

${ }^{2}$ Centre de Biologie Intégrative, CBI, Microscopie Electronique Intégrative, METi, CNRS, University of Toulouse, France.

\begin{abstract}
:
The twisted structures of the chitin-based cuticle of beetles confer on them specific optical characteristics. Intrigued by the observation of Bragg gratings with a depth-dependent periodicity in the cuticle of Chrysina beetles, we determine the experimental conditions leading to their transcription into cholesteric liquid crystal oligomers. We correlate the optical properties of reflectors thus produced with their internal morphology, as observed by transmission electron microscopy. With the use of a single parameter, the thermal annealing time, the reflection color is made time-tunable. Different spectral bands and reflection colors from golden yellow to NIR are available, and irreversibility of the final color is reached at the end. On the basis of the design concept and these properties, these hybrid chiral-achiral materials inspire the fabrication of smart reflective labels. When encapsulated in the package of a product to be kept in cold conditions, the label records the history of the product conservation. Two kinds of information based on color changes are recorded: qualitative information reporting that the product was kept outside of the specified storage temperature and
\end{abstract}


quantitative information giving an indication of the time elapsed since the temperature exceeded the storage temperature of the product.

KEYWORDS: cholesteric liquid crystals, photonic crystals, smart labels, time-temperature indicators, structural color, time-responsive reflective color, bioinspiration, structure-gradient materials.

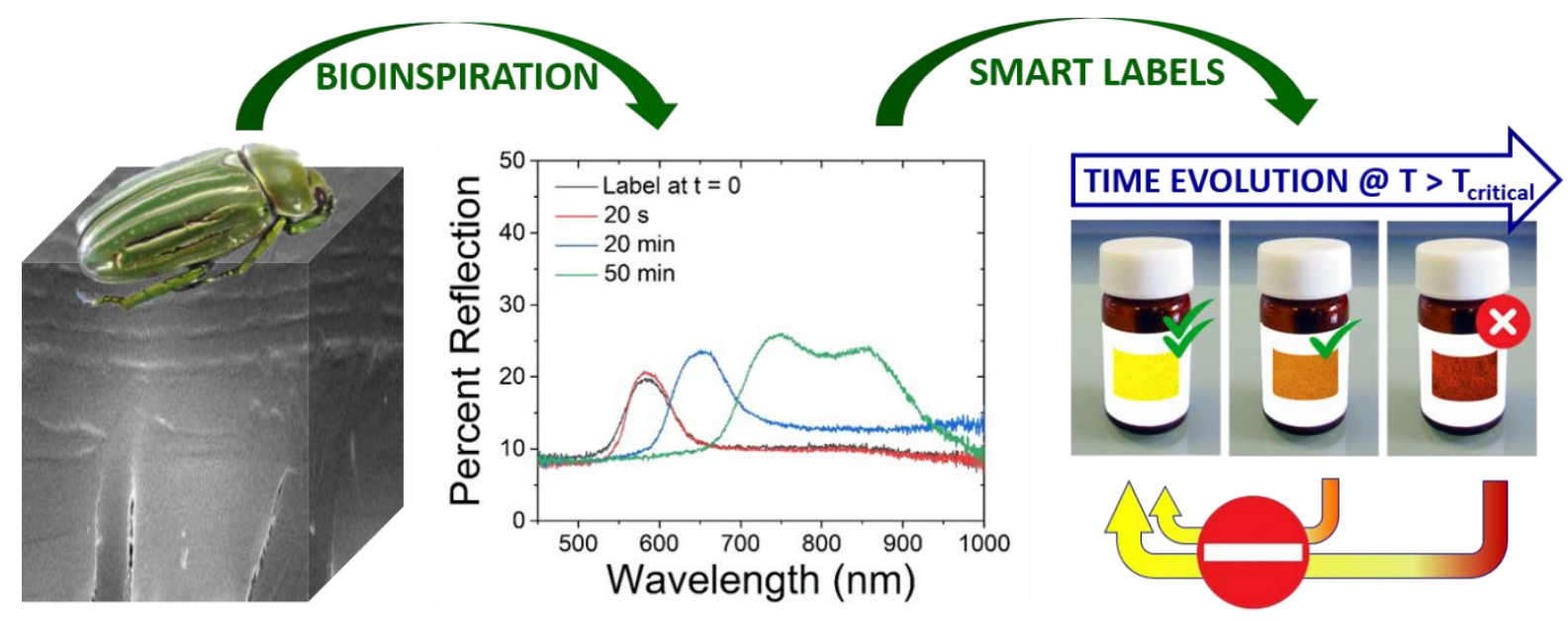

The morphology of the cuticles of beetles of the genus Chrysina inspires the design of reflectors combining twisted and untwisted structures. The resulting materials in turn inspire the fabrication of time temperature indicators that record the thermal history.

Received: May 4, 2021

Accepted: June 4, 2021

Published: June 16, 2021 


\section{INTRODUCTION}

Main features of cholesteric liquid crystals. Cholesteric liquid crystals (CLCs) are chiral materials that occupy a prominent place in the field of photonic crystals and optical materials, generally speaking, because of their helical molecular organization and specific properties ${ }^{1-4}$. First, CLCs exhibit double selectivity in wavelength and polarization. A cholesteric material may selectively reflect light, and the mean reflection wavelength $\lambda_{0}$ is related to the helical pitch $p$ (periodicity, which represents a $360^{\circ}$ rotation of the orientation of the rod-like molecules) by Bragg's law: $\lambda_{0}=n p \cos \theta$, where $n$ is the average refractive index and $\theta$ is the angle between the light propagation direction and the helical axis. Second, unlike common mirrors, which reverse the polarization of the light they reflect, the cholesteric planar texture reflects circularly polarized light with the same handedness as the twist of the helix, while light with the other polarization (50\% of the ambient unpolarized light at the selected wavelength) is transmitted and possesses the inverse handedness. This rule is known as the polarizationselectivity rule, and up to $50 \%$ of the ambient unpolarized light at the selected wavelength can be reflected. Third, an exceptional optical rotation may occur, up to $10^{3}$ to $10^{5} \% \mathrm{~mm}$ in the visible spectrum, compared with typical values between 0.01 and $100 \% \mathrm{~mm}$ for a chiral liquid (sugar water) or crystal (quartz). The wavelength regions for this optical activity are separated by the Bragg band and have opposite signs of rotation. A properly oriented slab of cholesteric material is thus a multifunctional material by acting as a selective filter, a vibrant-color reflector, a polarizer and an optical rotator.

Additionally, the optical properties of CLCs are tunable with control, which gives rise to a wide range of applications in the field of sensors ${ }^{5}$ : temperature ${ }^{6-10}$, pressure $^{11-13}$, light $^{14,15}$ or humidity ${ }^{16-18}$ sensors; electrically tunable bandpass filters ${ }^{19,20}$; polarizer-free reflective displays $^{21-23}$; and smart window prototypes ${ }^{24-26}$. 
Insect cuticles as cholesteric reflectors. Light reflection in the animal kingdom is diverse and ancient ${ }^{27}$. The earliest known reflectors, diffraction gratings, are 515 million years (Ma) old. Fossil beetle specimens ranging from $15-47$ Ma in age still reflect light ${ }^{28}$ because structural coloration is generally permanent and does not bleach like pigment colors. CLC structures are omnipresent in living matter, and many studies on this topic have focused on the insect cuticle ${ }^{29}$. The cuticle covers the insect body and consists of three main layers-epicuticle, exocuticle and endocuticle-secreted by a single layer of epidermal cells ${ }^{30}$. Both the exocuticle and endocuticle involve twisted CLC organization of chitin macromolecules, which causes a spatially varying index of refraction ${ }^{31}$. Chitin macromolecules form fibrils that wrap with proteins, and these fibril-protein associations assemble into fibers. Fibers assemble into bundles, which arrange parallel to each other to form pseudolayers. Finally, the pseudolayers assemble into a cholesteric structure, often referred to as the twisted plywood model from Bouligand $^{32,33}$ (Figure 1a). A continuous twist occurs along the axis perpendicular to the fibers, which interpenetrate from one pseudolayer to the next (this is why the term pseudolayer is preferred over layer). A $360^{\circ}$ rotation of the fiber orientation defines the helical pitch. When the structure is observed by optical or electron microscopy in a direction perpendicular to the helical axis, a fingerprint texture composed of parallel stripes may appear (as in Figure 1c). The distance between two identical stripes is related to the half-pitch of the twisted organization, not to the full pitch, because a $360^{\circ}$ rotation of the molecular orientation defines the pitch (Figure 1a).

In the search for biomimetic or bioinspired materials and devices, the structures and optical properties of insect cuticles are a first-rank source of inspiration for material scientists ${ }^{34,35}$.

Motivation of the research. The motivation of our research arises from the observation of electron microscopy images of cuticular structures in scarab beetles from the genus Chrysina, which show vibrant reflections from bright green to metallic silver-gold, including broadband 
a

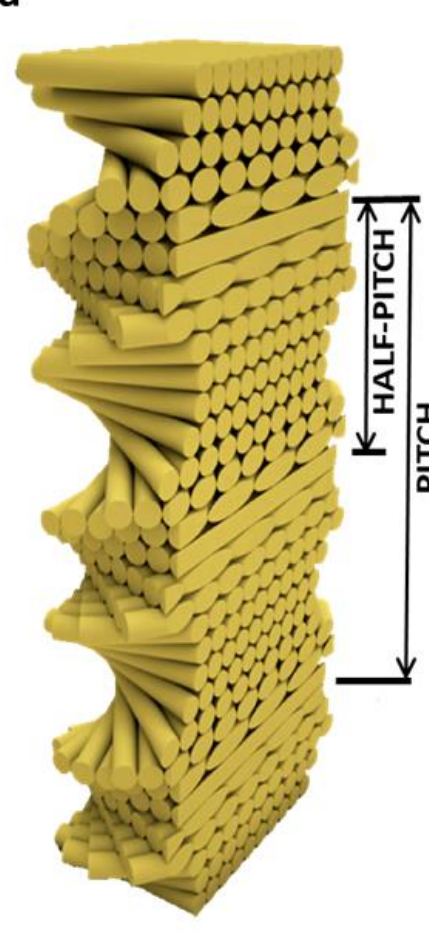

b
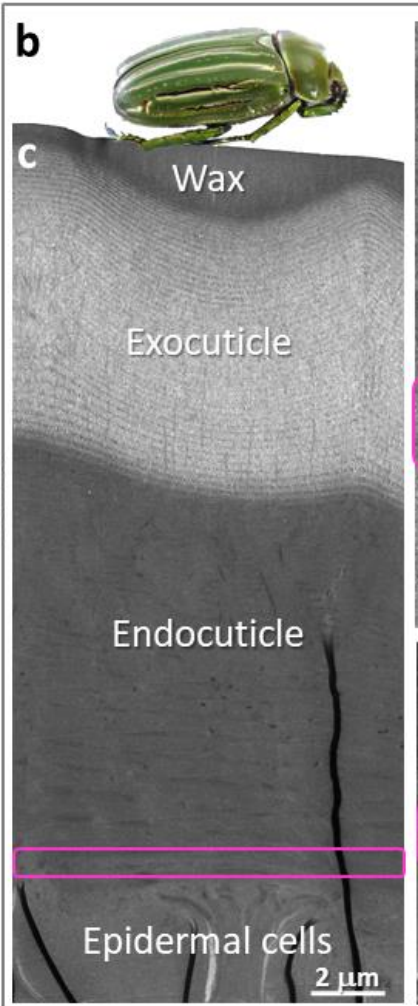
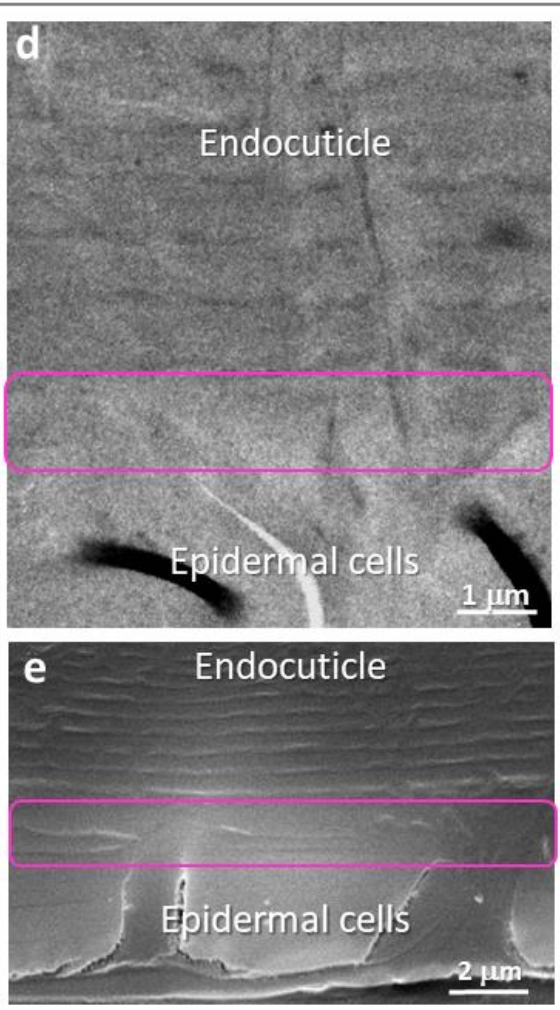

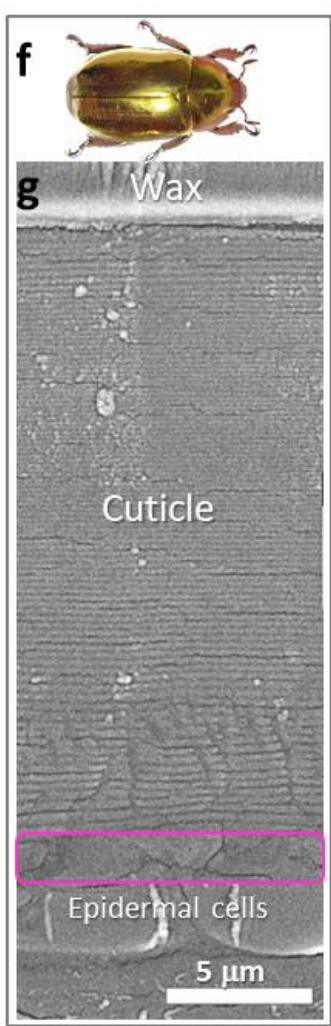

Figure 1. Origin of bioinspired reflectors. (a) Transverse cut of the twisted plywood model showing the relationship between the half-pitch and the distance between two stripes with the same orientation of rod-like building blocks. (Adapted from ref. 61. Reprinted with permission from AAAS.) (b) Chrysina gloriosa (Image by M. Mitov). (c) TEM view of the cuticle of $C$. gloriosa transverse to the verticality of a green band, which shows a wax layer ${ }^{62}$, the chitinbased part of the cuticle and the epidermis. Pink frames designate the interfacial region between the chitin-based cuticle and epidermal cells. Close-up (d) TEM and (e) SEM transverse views at the interface between the cuticle and the epidermal cells. (f) Chrysina aurigans. (Image by O. Boilly, Lille Natural History Museum, France. CC BY-SA 4.0.) (g) SEM transverse view of the cuticle of $C$. aurigans. (Adapted with permission from ref. 39. (C) 2014 The Optical Society).

reflections ${ }^{36}$. Here, we refer to the multiband-green and silver-cuticle of Chrysina gloriosa (Figure 1b) and the golden yellow cuticle of Chrysina aurigans (Figure 1f). Both cuticles of $C$. 
gloriosa $a^{37,38}$ and C. aurigans $^{39-42}$ are broadband reflectors from the beginning of the visible spectrum to the NIR spectrum. To our knowledge, the nature of the organization in the border zone (localized by pink frames in Figures 1c, d, e and g) between the end of the twisted region (fingerprint texture) and the epidermis has not been discussed in the literature. Continuity of the variation in the helical pitch in the thickness direction of the cuticle and of the orientation of the helical axis in the case of $C$. gloriosa ${ }^{43}$ remarkably occurs. It could thus be assumed that the end of the twisted structure does not occur abruptly but instead follows a structural gradient, as suggested by the image in Figure 1e showing the lowest stripes of the endocuticle of $C$. gloriosa: the stripes' contrast gradually fades, and then, the stripes disappear by being overwhelmed in a nonpatterned area. These incomplete lines embedded in a nonpatterned matrix could correspond to a frustrated CLC structure-prevented from complete twistingcoexisting with an unwound helix. Then, these lines are followed by an area without a pattern over a small thickness, which could correspond to a fully unwound helix, an area for which the helical pitch diverges, i.e., an achiral nematic LC (NLC) structure forced by geometric conditions that prevent the free development of a large-pitch helical structure. In this case, it would ensure a soft end to the twist of the chitin molecules. From the top to the bottom, the transverse structure of the chitinous part could thus consist of the coexistence of a pitch-gradient structure followed by a frustrated twisted structure and then a fully unwound helix, with the whole architecture being realized without the requirement of interfaces.

Our goal is not to answer stimulating questions on the morphogenesis of cuticular reflectors but instead to take inspiration from the above observations to design photonic materials with a controlled balance between chiral and achiral structures inside a single material exhibiting no discontinuity or interface - as in nature. We present a simple and effective method to fabricate bandgap-tunable reflective materials whose versatility of the characteristics of the Bragg band does not depend on temperature or external parameters but is underlain by this bioinspired 
approach. An optimal use of resources and a reduced number of stages during the fabrication procedure are targeted, in the spirit of eco-design as in nature. We aim to investigate the reflectance and transmittance properties of the bioinspired cholesteric materials in close relation to their transverse structure, as observed by TEM. Finally, a concrete use of materials based on the design of hybrid (chiral-achiral) structures in the field of time-temperature indicators is presented and discussed.

\section{RESULTS}

Formulation of LC mixtures. To formulate the CLC and NLC films in relation to our research objectives, we used LC photopolymerizable and crosslinkable oligomers with a siloxane backbone (Figures $2 \mathrm{a}$ and $\mathrm{b})^{44}$. They consist of a cyclic siloxane ring to which two types of side chains are attached via aliphatic spacers: an achiral mesogen and a chiral cholesterol-bearing mesogen (Figure 2a) or only achiral mesogens (Figure 2b). When formed into a thin film with a planar texture (the helical axis is perpendicular to the film), the reflection color of the cholesteric oligomer ranges from blue to red in relation to the molar percentage of chiral mesogens in the molecule and the ring size. The helical structure is left-handed. The glassy transition temperature is approximately $0^{\circ} \mathrm{C}$, and the clearing temperature is approximately $140^{\circ} \mathrm{C}$. After crosslinking, the reflection wavelength becomes nearly independent of the temperature in the range from $-196^{\circ} \mathrm{C}$ (liquid nitrogen) to $140^{\circ} \mathrm{C}$. The $\mathrm{CLC}$ of the present study was a blend made with 30 wt. \% of a blue-reflecting compound, silicon blue (SB) and $70 \mathrm{wt}$ \% of a red-reflecting compound, silicon red (SR). The composition of the mixture was chosen to fit the golden yellow color of the cuticle of $C$. aurigans. However, the concept underlaid by the present study is independent of the choice of the reflection color associated with the cholesteric mixture. The SB compound contains $65 \%$ oligomer a, $8 \%$ monomer c and $27 \%$ monomer $\mathbf{d}$. The SR compound contains $79 \%$ oligomer a and $21 \%$ 
monomer c. A nematic compound, silicon nematic (SN), containing $70 \%$ oligomer $\mathbf{b}$ and $30 \%$ monomer c, was used as provided by the supplier and is the NLC of the present study. Monomers $\mathbf{c}$ and $\mathbf{d}$ were added by the supplier to the oligomers to reduce their viscosity to facilitate their spreading on a plate in the form of thin films ${ }^{44}$. To the CLC and NLC, 0.6 wt. \% photoinitiator e and 2.0 wt. \% thermal inhibitor $\mathbf{f}$ were added.

a

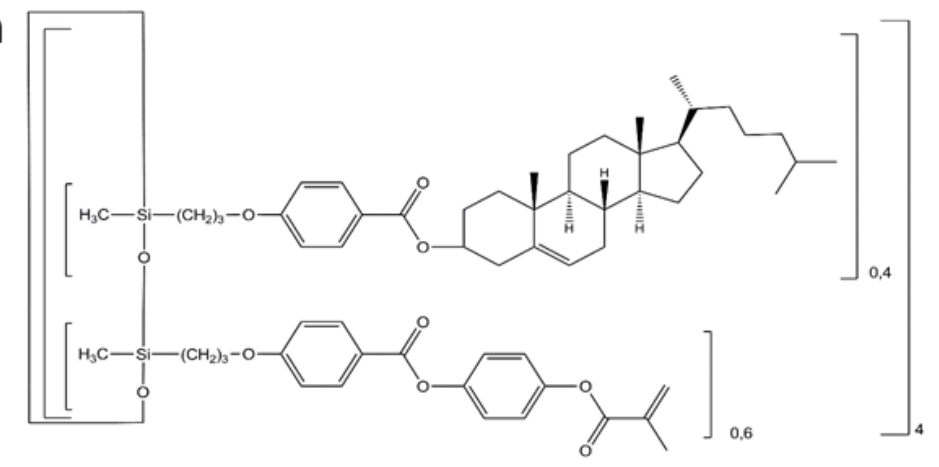

b

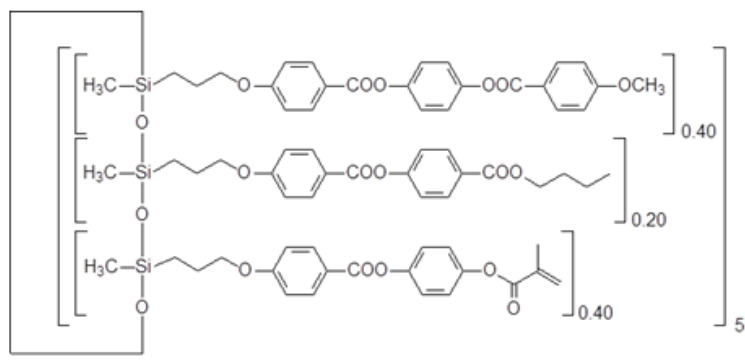

C

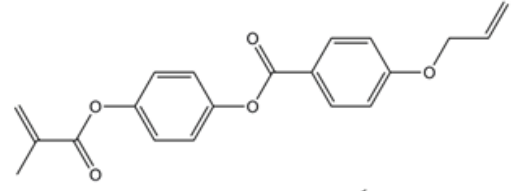

d

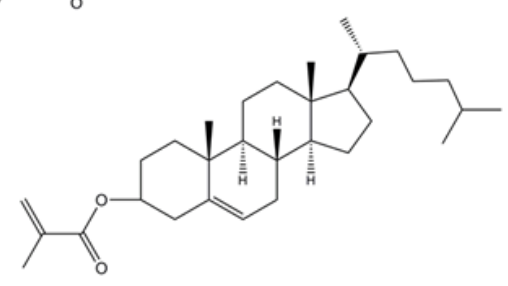

e

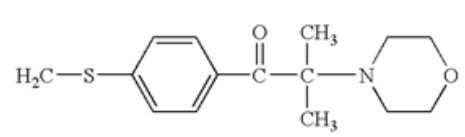

$\mathbf{f}$

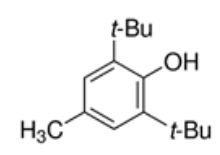

Figure 2. Chemical structures of used chemicals. Photopolymerizable and crosslinkable (a) cholesteric and (b) nematic liquid crystal siloxane-based oligomers. (c) and (d) Functional monomers. (e) Photoinitiator. (f) Thermal inhibitor.

Preparation of experimental cells. The constitution of the cells is shown in Figure 3a. Two open layers of CLC and NLC coated on a glass plate (see Experimental Section) face each other. The thickness of the CLC films $(14.0 \pm 1.0 \mu \mathrm{m})$ was chosen to be almost twice the thickness of the NLC $(7.5 \pm 0.5 \mu \mathrm{m})$. Spacers $12.5 \mu \mathrm{m}$ thick were inserted between the plates. After closing 
the cell at room temperature, the open surfaces of the layers were in contact. The cell was then placed on a heating stage at $60^{\circ} \mathrm{C}$. To describe the time-dependent optical and structural properties of the system, five scenarios are presented in which the annealing time was varied from $20 \mathrm{~s}$ to $50 \mathrm{~min}$. Placing two LC substances between a pair of transparent substrates into contact to generate a concentration gradient allows us to obtain a qualitative overview of some optical textures present in the mixture ${ }^{45}$. Figure $3 b$ displays an optical micrograph showing a concentration gradient between the CLC and NLC compounds in the $x-y$ plane of the substrates. The purpose is to find the conditions for generating a temporal concentration gradient between the layers of chiral and achiral materials in the $z$-direction perpendicular to the layers; this event has to occur at a thickness several dozen times thinner than the height of the region imaged in Figure $3 b$.

When the targeted time is reached, the soft material is polymerized and crosslinked with UV light (see the Experimental section). The optical properties of the material are thus fixed into an elastomeric layer, which can be cut in a transverse direction in 150-nm-thick slices to allow TEM imaging of its internal structure.
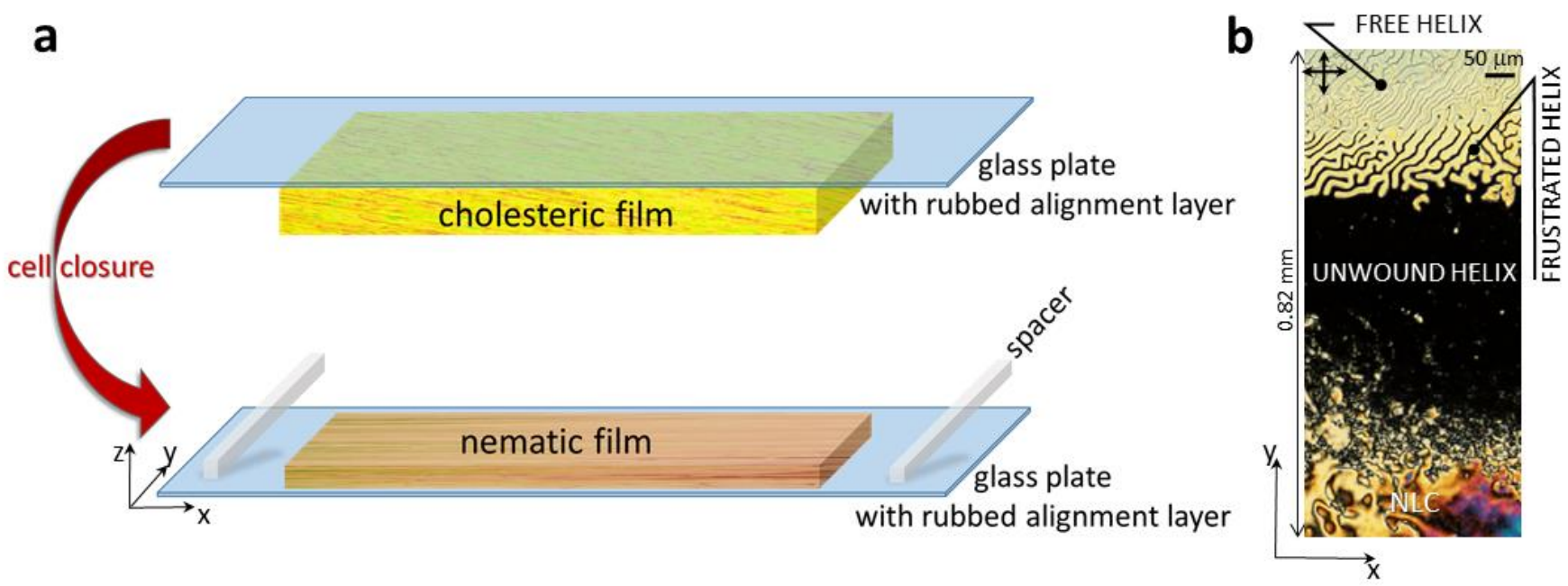

Figure 3. Representation of the structure gradient to target along with the experimental cell used for this purpose. (a) Experimental cell. (b) Optical micrograph in a planar geometry of 
contact preparation between the CLC and NLC of the study showing the different phases and patterns as a consequence of a concentration gradient between the two compounds (transmission mode, crossed polarizers; the black arrows indicate the orientation of the crossed polarizers). The CLC texture is in the upper part and out of the image. The schlieren texture inherent to the NLC is visible in the lower part. The textures follow one another from the top to the bottom as follows: fingerprint texture (the helix is free to develop); cholesteric fingers in a black matrix that corresponds to an unwound helix (frustrated helix); black texture (unwound helix); and NLC texture.

Optical properties of the CLC-NLC cells. The textures and reflection spectra of five cells plus the pristine CLC film after UV polymerization and crosslinking are shown in Figure 4.

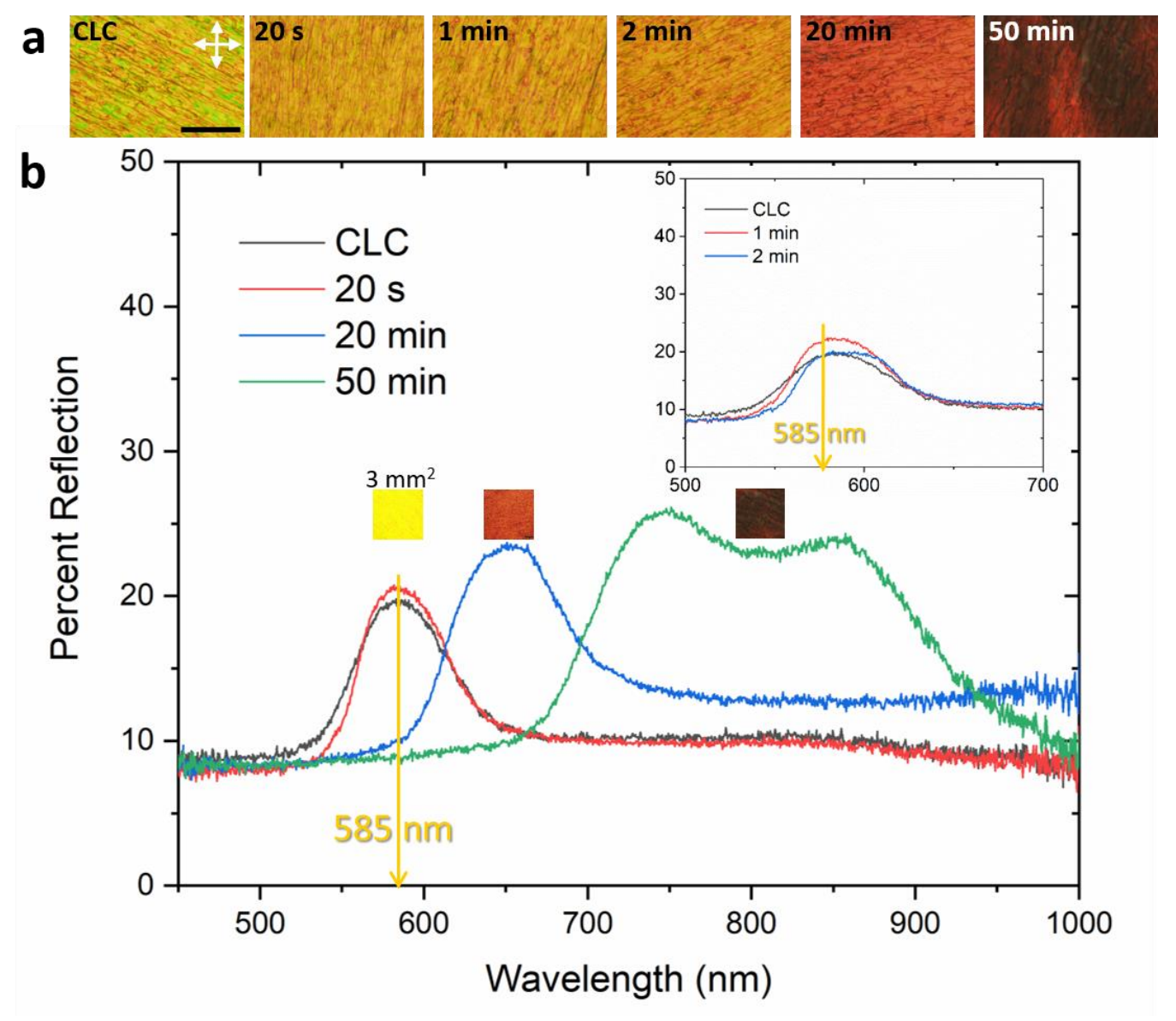


Figure 4. Reflection properties of the cells for different annealing times and at normal incidence. (a) Optical textures (reflection mode, crossed polarizers). The white arrows indicate the orientation of the crossed polarizers. Scale bar $=50 \mu \mathrm{m}$. (b) Reflection spectra.

The reflectance is displayed between 0 and $50 \%$ with regard to the polarization-selectivity rule (see Introduction); the signal level of the spectra is $8-10 \%$ due to the reflectance of the cover glass plate (which was not taken into account in the baseline). The mean wavelength of the Bragg band allocated to the golden yellow CLC film is $585 \mathrm{~nm}$. The bandgap limits $\lambda_{\text {MIN }}$ and $\lambda_{\operatorname{MAX}}$ (Figure 5), determined at the half-height of the reflection peak, are 555-620 nm (CLC film), 560-620 nm (20 s), 560-615 nm (1 min) and 560-625 nm (2 min), which means that the diffusion between the CLC and NLC films up to $2 \mathrm{~min}$ is not sufficient to significantly modify the position of the Bragg band inherent to the CLC film. A clear-cut bandgap shift is visible at $20 \mathrm{~min}$ in Figure 4, with a mean reflection peak at $650 \mathrm{~nm}$ (red color). Some light reflection is present above $700 \mathrm{~nm}$ (the signal level does not return to 10\%): as shown in the following section by TEM, the 20-min sample exhibits a pitch gradient; however, the number of helix turns ascribed to the twist in this spectral region is too low to allow a significant contribution to the Bragg band from this part of the pitch gradient. The reflectance depends on the number of pitches (i.e., the number of helix turns), which means that the twist needs to develop within a minimal film thickness to enable the appearance of Bragg reflections that are detectable under standard spectrophotometry conditions ${ }^{46}$. Annealing the cell for 50 min gives rise to an enlarged Bragg band with $\lambda_{\text {MIN }}$ and $\lambda_{\text {MAx }}$ equal to $690 \mathrm{~nm}$ and $915 \mathrm{~nm}$, from dark red to near-IR. The bandgap $\Delta \lambda=\lambda_{\text {MAX }}-\lambda_{\text {MIN }}$ varies from 65 to $220 \mathrm{~nm}$ from the pristine golden film to the 50 -min red film (inset in Figure 5). The present set of annealing times thus allows the fabrication of different cells with a structural color ranging from golden yellow to the near-IR for a single material with the same chemical composition from one cell to another, the difference only lying 
in the time. An NLC is usually considered a CLC with an infinite pitch, and the pitch of a CLC can be augmented by adding a quantity of $\mathrm{NLC}^{47,48}$. Here, spatially directed dissolution of CLC and NLC layers occurs in the transverse direction inside a single material, similar to the result of the design of a gradient-structure material. From $0 \mathrm{~s}$ to $50 \mathrm{~min}, \lambda_{\mathrm{MAx}}$ undergoes a stronger amplitude increase than does $\lambda_{\text {MIN }}: 295 \mathrm{~nm} v s .135 \mathrm{~nm}$ (Figure 5). It may be expected that this graded stretching of the Bragg band from its red part is the consequence of the graded dissolution between a constant-pitch cholesteric LC and an infinite-pitch cholesteric LC.

Transmission spectra and textures are given in Figure S1. Negative peaks occur in spectral bands comparable to those of the positive peaks assigned to the reflection. Transmission investigations mainly provide additional information about the evolution of the transmittance with time (details are given in the caption of Figure S1).

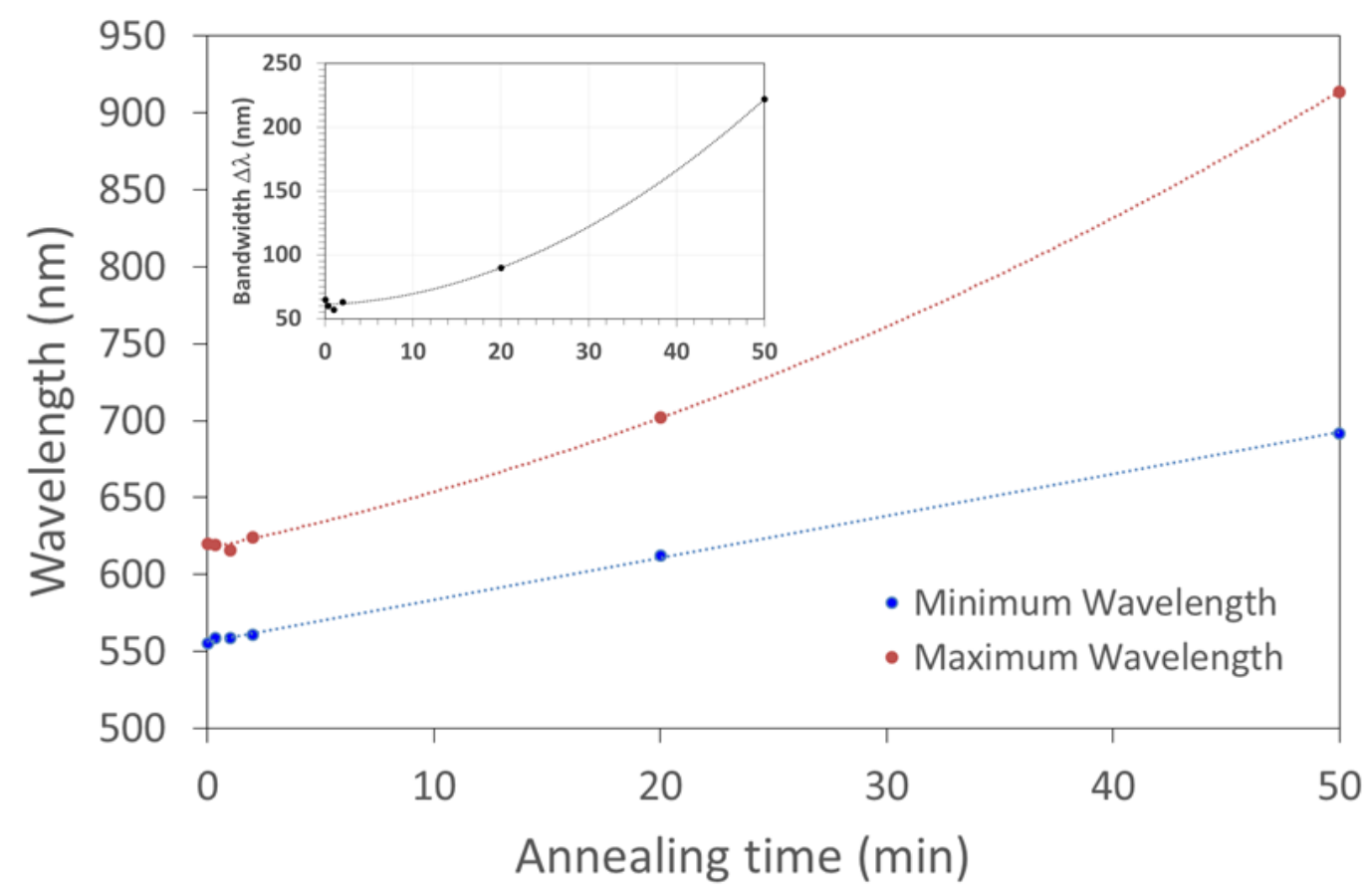

Figure 5. Bandgap limits of reflection spectra as a function of the annealing time. Inset: bandwidth as a function of the annealing time. 
TEM investigations of the internal structure of different CLC-NLC films. By taking advantage of the solid nature of the material, TEM allows us to correlate the temporal behavior of reflection properties with the internal structure of CLC-NLC films. TEM imaging of cholesteric polysiloxane-based oligomers reveals the typical fingerprint texture ${ }^{49}$, similar to observations made by optical microscopy (Figure 3b). However, the periodic bright-and-dark contrast in TEM is the result of several processes, including mainly mass loss during irradiation acting as selective etching ${ }^{50}$. Figure 6 shows the TEM textures of cross-sections accompanied by the variation in the half-pitch (distance between two bright stripes) along the depth.
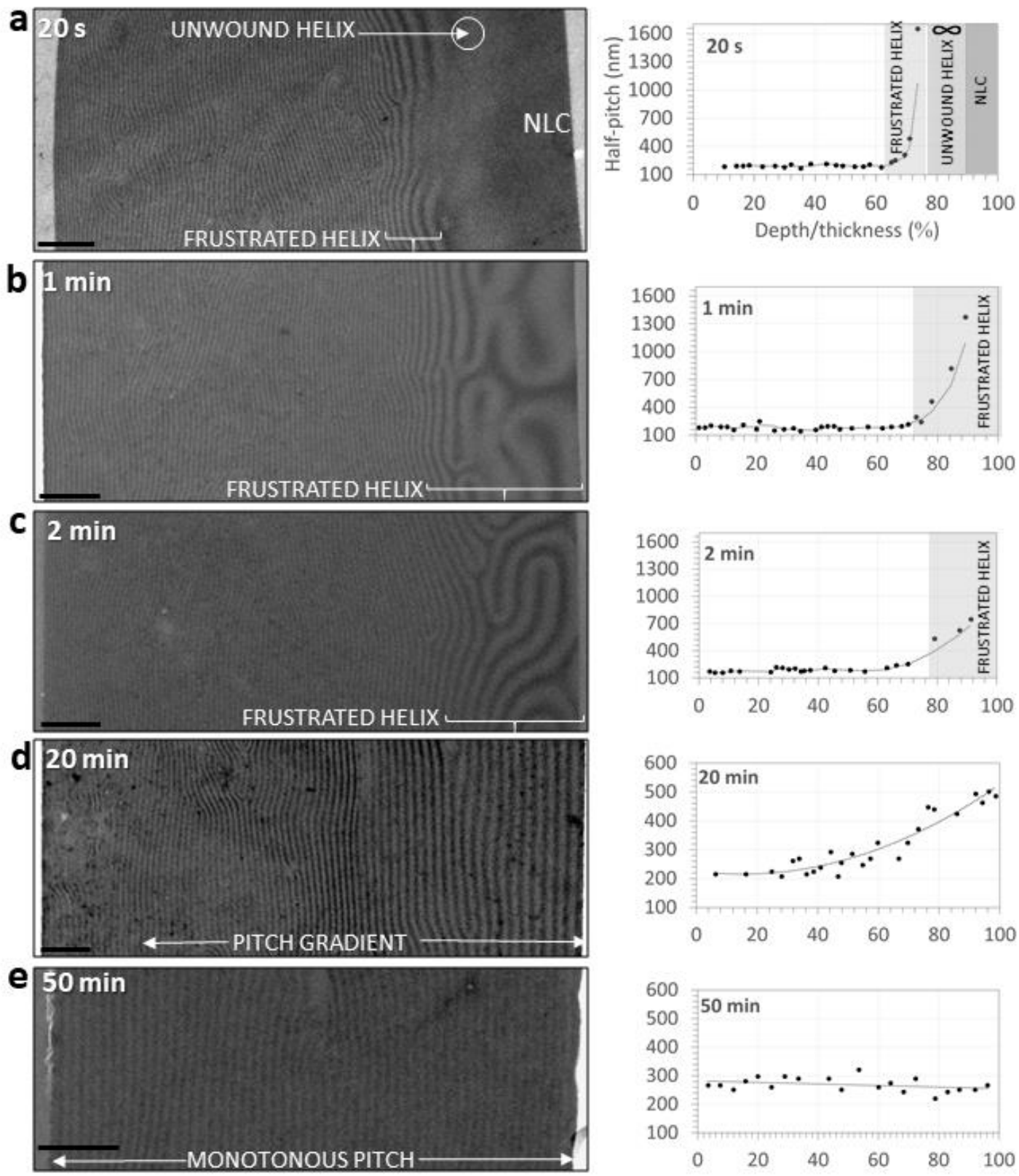
Figure 6. Structural analysis of samples. TEM transverse views accompanied by the half-pitch (distance between two bright stripes) as a function of the normalized depth (depth over the total thickness of the sample) for different annealing times. The half-pitch range differs from the $20 \mathrm{~s}-1 \mathrm{~min}-2 \mathrm{~min}$ samples (a to c) to the $20 \mathrm{~min}-50 \mathrm{~min}$ ( $\mathrm{d}$ and e) for representation purposes (the pitch changes in two different ranges). Scale bar $=2 \mu \mathrm{m}$.

Different regimes in the thermal diffusion between the chiral and achiral layers are revealed. Let us first remark that the sample thickness may differ from one case of annealing to another (Table S1), in particular because the film laterally spreads out when the annealing time increases. For this reason, we choose for the abscissa a normalized range (depth over the total thickness of the sample) to display the pitch variation for comparison from sample to sample of the pitch variation in the whole volume of the sample. The zero abscissa is chosen as the top of the CLC film. At a short annealing time (20 s), the whole set of bioinspired, target structures is visible (Figure 6a). From the CLC layer (at the left side of the image) to the NLC layer, the following structures successively occur: a fingerprint texture related to a constant pitch of approximately $360 \mathrm{~nm}$, a frustrated fingerprint texture that materializes as deformed and larger bright-and-dark cholesteric fingers, an unwound cholesteric helix that materialize as a bright halo without stripes and the pure NLC (for reference, the TEM image of the NLC material alone is shown in Figure S2a). The term cholesteric fingers is often used in the case of strong frustration of the helical structure when the stripes are separated by homeotropic regions, which correspond to local unwinding of the helix with molecules perpendicular to the surfaces of the CLC film ${ }^{51,52}$; the helix is unwound when the film thickness is close to the pitch or above it. At 1 min (Figure 6b), the fingerprint texture with a near-constant pitch is followed by a region corresponding to a CLC-NLC gradient in which the helix is frustrated; this event occurs over a thicker thickness compared to the same kind of region at $20 \mathrm{~s}$ (this is the result of progressive 
diffusion). The textural pitch progressively increases and gives rise to umbilical structures for which the direction of the stripes is no longer parallel to the film surfaces. The NLC layer disappears due to it being consumed in the course of rapid thermal diffusion. The situation at 2 min (Figure 2c) is quite similar; the curve shows that the stripe periodicity is lowered compared to that at $1 \mathrm{~min}$. A third situation is shown at $20 \mathrm{~min}$ (Figure $6 \mathrm{~d}$ ): the sample no longer includes frustration of the helix but instead a pitch gradient from $430 \mathrm{~nm}$ to $1000 \mathrm{~nm}$, from approximately $32 \%$ of the thickness to the end of the film. Finally, a cholesteric structure with a nearly constant 540-nm pitch is obtained at $50 \mathrm{~min}$ (Figure 6e). The pitch value is 1.5 times larger than that inherent to the CLC film, similar to the result of full mixing of CLC and NLC layers.

To summarize, the annealing process presents four stages: (a) the coexistence of a constant-pitch helix, a frustrated helix, a (nematic-like) unwound helix and a nematic structure made from the pure NLC compound; (b-c) the coexistence of a constant-pitch helix followed by a frustrated helix; (d) the coexistence of a constant-pitch helix (over approximately one-third of the thickness) followed by a pitch-gradient helix; and (e) a quasi-constant-pitch helix.

\section{DISCUSSION}

The association of LC layers was realized in the literature by using cholesteric layers with the goal of broadening the characteristics of the Bragg band ${ }^{3}$, mainly the wavelength band. Two cases were considered with regard to the discontinuous or continuous (interface-free) nature of the final architecture: stacking of layers leading to a multilayer system ${ }^{53,54}$ and thermal diffusion between a pair of layers with distinct Bragg bands, in which diffusion aims to broaden the bandgap by covering the pristine bandgaps and the wavelengths in between ${ }^{55,56}$. Our system differs from the latter case by involving a chiral layer along with an achiral layer and a diffusion process leading to different cases of narrow-band Bragg reflectors. This last characteristic is relevant for applications aimed at the field of time-temperature indicators that we discuss below. 
We searched for an experimental protocol in which the reflection band was tunable by controlled interpenetration of cholesteric and nematic layers. The first layer defines the left limit of the Bragg band and is not intended to stay fixed in the course of the annealing process. The role of the second layer is to allow different scenarios for the behavior of the Bragg band that are not achievable with two CLC layers: increasing the helical pitch up to an infinite pitch, realizing a variable-pitch twisted structure, and finally realizing a constant-pitch CLC.

Time-temperature indicators record the thermal history ${ }^{57}$. Our design inspired us to realize such smart devices on the basis of the graded, irreversible evolution with temperature and time of the label color (i.e., the pristine bilayer of the present study encapsulated in a plastic matrix or carrier). Usual temperature-variable cholesteric labels (LC thermometers ${ }^{58}$ ) do not have this dual property with added irreversibility, which is of paramount importance for this kind of application. We may name these indicators cholesteric cookies by analogy with the web cookies designed to record a user's browsing activity. When tagged on the package of a food product or medicine - such as vaccines to be stored and transported under ultracold conditions ${ }^{59}$ - to be kept in a precise low temperature range, the color of the cholesteric indicator is frozen because the diffusion between layers is forbidden (in our case, the glassy transition temperature of LC oligomers under study is approximately $0^{\circ} \mathrm{C}$ ). When the temperature of the product goes beyond a critical value defined in relation to the product specifications, the label color changes, and this color evolves with time. These color changes reveal to the potential user that the thermal chain has been broken and, in addition, could give an indication of the time since the temperature exceeded the storage temperature range of the product. The user would have at her/his disposal a color chart giving the relationship between color, temperature and time. The fact that the label will never return to its initial color, regardless of what the handler does, is fundamentally based on the physical interdiffusion between chiral and achiral materials. In addition to a temperature-time tunability stage, an irreversibility stage is necessary. Formulation of the 
properties of the label layers (chemical composition, thickness) in their native state in relation to the temperature-color variation desired by the manufacturer is required.

\section{CONCLUSIONS}

We have designed wavelength-selective cholesteric reflectors by determining the experimental conditions leading to a fine balance between helical, distorted helical and unwound helical structures in the bulk of an interface-free polymer film. Four scenarios were described: (i) constant-pitch helix — frustrated helix - unwound helix (forced nematic structure)—stable nematic structure; (ii) constant-pitch helix — frustrated helix; (iii) pitch-gradient helix; and (iv) monotonic-pitch helix. Obtaining one scenario or another scenario at a constant temperature depends on a single parameter-time. Different spectral bands and reflection colors from golden yellow to NIR are available, and irreversibility of the final color is reached at the end. The combination of these properties precisely inspired us to use the concept of chiral-achiral hybrid structures for the manufacturing of cholesteric labels. When encapsulated in the package of a product to be kept in cold conditions, the smart label records the history of the product conservation. Two kinds of information based on color changes are recorded: qualitative information reporting that the product was kept outside of the specified storage temperature and quantitative information giving an indication of the time elapsed since the temperature exceeded the storage temperature of the product.

\section{EXPERIMENTAL SECTION}

Specimen of Chrysina gloriosa. A male specimen of Chrysina gloriosa was collected at Madera Canyon (Santa Cruz County, Arizona, USA) in July 2014. 
Materials. LC photocrosslinkable side-chain oligomers with a siloxane backbone were obtained from Wacker-Chemie GmbH, Munich, Germany. The photoinitiator Irgacure ${ }^{\circledR} 907$ was purchased from Ciba Specialty Chemicals Inc. The thermal polymerization inhibitor BHT was purchased from Sigma-Aldrich (W218405). Kapton sheets for spacers were provided by Micel.

Treatment of glass plates. A polyvinyl alcohol (PVA) solution layer formed on $150-\mu \mathrm{m}$-thick glass plates supporting the LC films was used as a promoter of planar alignment of the molecules and as a sacrificial layer to obtain free-standing films after the sample was placed in water. PVA as a powder (P8136, Sigma-Aldrich) was dissolved at 8 wt. \% in distilled water. The aqueous solution was stirred and deposited on plates using a spin coater (Ossila Ltd.). A single sequence of spin-coating consisted of the deposition of $0.20 \mathrm{ml}$ of solution during a program consisting of three sequences with the following spin rates and durations: 5000 rpm@20s_4000 rpm@40 s_-3000 rpm@60 s. This operation was repeated two times. The thickness of the dried film was approximately $2 \mu \mathrm{m}$. The film was finally rubbed three times with a rayon cloth (YA-20R, Yoshikawa Chemical Company, Ltd.).

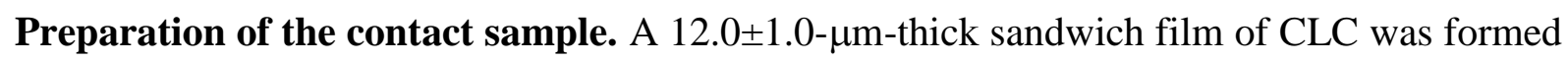
at $60^{\circ} \mathrm{C}$ between untreated glass plates. The NLC was inserted at $80^{\circ} \mathrm{C}$ by capillarity into the cell. The cell was annealed at $73^{\circ} \mathrm{C}$ for 15 hours. The image in Figure $3 \mathrm{~b}$ was taken at $80^{\circ} \mathrm{C}$.

Preparation of individual films. Two distinct 585-nm-reflecting CLC and transparent NLC samples were prepared on a heating stage at $80^{\circ} \mathrm{C}$. The NLC was used as provided by the supplier. The CLC was a blend made with 30 wt. \% of a blue-reflecting compound (SB) and 70 wt. \% of a red-reflecting compound (SR). To the CLC blend and NLC compound, 0.6 wt. \% of 
the photoinitiator Irgacure ${ }^{\odot} 907$ and $2.0 \mathrm{wt} . \%$ of the thermal polymerization inhibitor BHT were added. A 14 $\pm 1-\mu m$-thick sandwich film of CLC was formed between two treated glass plates and annealed at $80^{\circ} \mathrm{C}$. A $7.5 \pm 0.5-\mu \mathrm{m}$-thick sandwich film of $\mathrm{SN}$ was formed between two plates and annealed at $100^{\circ} \mathrm{C}$. The thickness was measured by the interference method (based on the wave interference due to the internal reflection between the two inner surfaces of the cell substrates ${ }^{60}$ ). The dispersion in thickness of the individual CLC and NLC films constituting the five samples was kept as low as possible. Special care was taken to ensure that the NLC films had a monodomain texture (Figure S2b) and exhibited a very high transmission (90\%-Figure S3). To remove one plate and obtain open films while avoiding the formation of scratches on the surface of the film, the sandwich cells were kept at low temperature in a refrigerator; one of the plates was sharply removed from the film with the aid of a Handi-Vac ${ }^{\circledR}$ coverslip pick-up tool (Ted Pella, Inc.). That the free surface of the film remained smooth after the operation was checked by optical microscopy.

Polymerization conditions. The films were placed at $60^{\circ} \mathrm{C}$ on a heating stage and irradiated with UV light for 10 minutes with a maximum intensity at $365 \mathrm{~nm}$ equal to $0.50 \mathrm{~mW} / \mathrm{cm}^{2}$.

Inclusions of synthetic samples for ultramicrotomy. To obtain free-standing films ready to be embedded in a piece of resin, each sample was placed in a vial of distilled water for 1 day. Due to the presence of water-soluble PVA layers, the films detached as a block from the plates while maintaining clear-cut surfaces, as verified by TEM transverse views. A small piece of material was embedded in EMbed-812 resin (Electron Microscopy Sciences), which was then cured at $62^{\circ} \mathrm{C}$ for 2 days. 
Inclusions of biological samples for ultramicrotomy. The cuticle samples corresponded to the elytra and were removed with a razor blade. A small piece of material was embedded in EMbed-812 resin (Electron Microscopy Sciences), which was then cured at $62^{\circ} \mathrm{C}$ for 2 days.

Preparation of biological samples for TEM by ultramicrotomy. A diamond knife at ambient temperature was used to cut 80-nm-thick slices (Figure 1c) or 120-nm-thick slices (Figure 1d) with a Leica UCT ultramicrotome. The samples were cut perpendicular to the film surface (cross-sections). Slices were placed on single-slot Formvar-coated copper grids (GS2x1-C3, Gilder Grids Ltd.) and stained with UranyLess (brand mixture of lanthanides from Delta microscopy) for $20 \mathrm{~min}$ and with 3\% Reynolds lead citrate (from Chromalys) for $5 \mathrm{~min}$.

Preparation of synthetic samples for TEM by ultramicrotomy. A diamond knife at ambient temperature was used to cut 150-nm-thick ultrathin slices with a Leica UCT ultramicrotome. The material was cut perpendicular to the film surface (cross-sections). Slices were placed on single-slot Formvar-coated copper grids (GS2x1-C3, Gilder Grids Ltd.).

TEM conditions. A Jeol JEM-1400 microscope operating at $80 \mathrm{kV}$ equipped with a Gatan Orius SC1000B CCD camera was used.

Periodicity profiles from TEM images. Quantitative image analysis was performed with DigitalMicrograph software from Gatan. The intensities of the gray levels on a given surface of the images (typical surface $=8 \times 18 \mu \mathrm{m}^{2}$ ) were analyzed using the Profile option. The distance between two consecutive positive or negative peaks corresponded to the distance between two successive stripes of the same contrast in the fingerprint texture. Positive (resp. negative) peaks correspond to bright (resp. dark) stripes because the transmitted light is higher (resp. lower) in 
bright (resp. dark) stripes. Peaks were excluded from the analysis when they corresponded to intensity changes related to noisy peaks for which the measurement was questionable (this explains why experimental points are sometimes lacking in Figures 6a to e).

SEM conditions. A Zeiss 1540 XB Crossbeam SEM equipped with a low-energy-capable focused ion beam (FIB) column was used (Figure 1e). WD $=4.9 \mathrm{~mm} . \mathrm{EHT}=20 \mathrm{kV}$.

Optical micrographs. Textures were photographed with an Olympus BX51 stereomicroscope equipped with an Olympus DP73 digital camera. A 50x objective with a numerical aperture (NA) of 0.50 was used.

Optical measurements. The reflectance and transmittance spectra of the materials were collected at RT and normal incidence with unpolarized incident light (halogen source HL-2000 from Mikropack GmbH emitting from $360 \mathrm{~nm}$ to $1700 \mathrm{~nm}$ ). An HR2000CG-UV-NIR spectrophotometer from Ocean Optics was used. Baselines were recorded with air (resp. a mirror) in the beam path for transmittance (resp. reflectance) measurements.

\section{ASSOCIATED CONTENT}

Supporting Information

The Supporting Information is available free of charge at:

https://pubs.acs.org/doi/10.1021/acsami.1c08218

Transmission properties of the cells for different annealing times; TEM and optical textures of the NLC sample; Typical transmission spectrum of an individual NLC film; Thickness of CLC and NLC individual films and samples after polymerization (PDF). 


\section{AUTHOR INFORMATION}

\section{Corresponding Author}

*E-mail: mitov@cemes.fr

\section{ORCID}

Michel Mitov: 0000-0003-1831-2152

\section{Author Contributions}

C. B. contributed to the development of samples, carried out the manufacture of samples and cells along with their optical characterization, and participated in the collection of data and in the analysis of results. V. S. prepared and cut the inclusions by ultramicrotomy and carried out TEM observations. M. M. led the conceptual development of the research, oversaw data collection, performed the analysis of results, organized the content of the manuscript, prepared the figures and wrote the manuscript. All authors revised the manuscript and gave approval to the final version.

\section{Notes}

The authors declare no competing financial interest.

\section{ACKNOWLEDGMENTS}

This work was financially supported by the Agence Nationale de la Recherche, France (COLEOPTIX, ANR-17-CE30-0025). M. M. thanks Dr. E. Hanelt from Wacker-Chemie GmbH (Munich, Germany) for providing him with oligomers. Mr P. Salles is acknowledged for acquiring the SEM image (Figure 1e). 


\section{REFERENCES}

(1) Kelker, H., Hatz, R. Optical Properties of Optically Active Mesophases, in Handbook of Liquid Crystals, 293-337; Verlag Chemie: Weinheim, Germany, 1980.

(2) Dierking, I. The Cholesteric Phase, in Textures of Liquid Crystals, 54-74; Wiley-VCH: Weinheim, Germany, 2003.

(3) Mitov, M. Cholesteric Liquid Crystals with a Broad Light Reflection Band. Adv. Mat. 2012, 24, 6260-6276.

(4) Balamurugan, R; Liu, J. H. A Review of the Fabrication of Photonic Band Gap Materials Based on Cholesteric Liquid Crystals. Reactive \& Funct. Polym. 2016, 105, 9-34

(5) Liquid Crystal Sensors, Schenning, A. P. H. J.; Crawford, G. P.; Broer, D. J., Eds.; Taylor and Francis, 2018.

(6) Ogiwara, A.; Kakiuchida, H. Thermally Tunable Light Filter Composed of Cholesteric Liquid Crystals with Different Temperature Dependence. Solar Energy Mat. Solar Cells 2016, $157,250-258$.

(7) Khandelwal, H; van Heeswijk, E. P. A.; Schenning, A. P. H. J.; Debije, M. G. Paintable Temperature-Responsive Cholesteric Liquid Crystal Reflectors Encapsulated on a Single Flexible Polymer Substrate. J. Mat. Chem. C 2019, 7, 7395-7398.

(8) Ranjkesh, A; Yoon, T.-H. Fabrication of a Single-Substrate Flexible Thermoresponsive Cholesteric Liquid-Crystal Film with Wavelength Tunability. ACS Appl. Mater. Interfaces 2019, 11, 26314-26322.

(9) Kragt, A. J. J.; Zuurbier, N. C. M.; Broer, D. J.; Schenning, A. P. H. J. TemperatureResponsive, Multicolor-Changing Photonic Polymers. ACS Appl. Mater. Interfaces 2019, 11, $28172-28179$. 
(10) Zhang, W.; Froyen, A. A. F.; Schenning, A. P. H. J.; Zhou, G.; Debije, M. G.; de Haan, L. T. Temperature-Responsive Photonic Devices Based on Cholesteric Liquid Crystals. Adv. Photon. Res. 2021, DOI: 10.1002/adpr.202100016.

(11) Shibaev, P. V.; Rivera, P.; Teter, D.; Marsico, S.; Sanzari, M.; Ramakrishnan, V.; Hanelt, E. Color Changing and Lasing Stretchable Cholesteric Films. Opt. Express 2008, 16, 29652970.

(12) Shibaev, P. V.; Schlesier, C.; Uhrlass, R.; Woodward, S.; Hanelt, E. Cholesteric Materials with Photonic Band Gap Sensitive to Shear Deformation and Mechanical Sensors. Liq. Cryst. 2010, 7, 1601-1604.

(13) Liu, Z.-P.; He, X.-Z.; Cong, Y.-H.; Zhang, B.-Y.; Meng, F.-B.; Tian, M.; Jia; Y.-G. Synthesis and Characterization of Two Series of Pressure-Sensitive Cholesteric Liquid Crystal Elastomers with Optical Properties. Liq. Cryst. 2020, 47, 143-153.

(14) Kim, Y; Tamaoki, N. Photoresponsive Chiral Dopants: Light-Driven Helicity Manipulation in Cholesteric Liquid Crystals for Optical and Mechanical Functions. ChemPhotoChem 2019, 3, 284-303.

(15) Ryabchun, A.; Lancia, F.; Katsonis, N. Light-Fueled Nanoscale Surface Waving in Chiral Liquid Crystal Networks. ACS Appl. Mater. Interfaces 2021, 13, 4777-4784.

(16) Saha, A.; Tanaka, Y.; Han, Y.; Bastiaansen, C. M. W.; Broer, D. J.; Sijbesma, R. P. Irreversible Visual Sensing of Humidity Using a Cholesteric Liquid Crystal. Chem. Comm. 2012, 48, 4579-4581.

(17) Moirangthem, M.; Schenning, A. P. H. J. Full Color Camouflage in a Printable Photonic Blue-Colored Polymer. ACS Appl. Mater. Interfaces 2018, 10, 4168-4172.

(18) Deng, Z.; Zhou, G.; de Haan, L. T. Preparation of an Interpenetrating Network of a Poly(ampholyte) and a Cholesteric Polymer and Investigation of Its Hydrochromic Properties, ACS Appl. Mater. Interfaces 2019, 11, 36044-36051. 
(19) Wu, P.-C.; Hsiao, C.-Y. ; Lee, W. Photonic Bandgap-Cholesteric Device with Electrical Tunability and Optical Tristability in Its Defect Modes. Crystals 2017, 7, 184.

(20) Nava, G. ; Ciciulla, F. ; Simoni, F. ; Iadlovska, O. ; Lavrentovich, O. D.; Heliconical Cholesteric Liquid Crystals as Electrically Tunable Optical Filters in Notch and Bandpass Configurations. Liq. Cryst. 2021, DOI: 10.1080/02678292.2021.1884911.

(21) Wu, S.-T.; Yang, D.-K. Reflective Liquid Crystal Displays; John Wiley \& Sons Ltd: Chichester, England, 2001.

(22) Yang, D.-K. Review of Operating Principle and Performance of Polarizer-Free Reflective Liquid-Crystal Displays. J. SID 2008, 16, 117-124.

(23) Coates, D. Cholesteric Reflective Displays, in Handbook of Visual Display Technology; 1545-1564; Chen, J.; Cranton, W.; Fihn, M., Eds.; Springer-Verlag: Berlin, Heidelberg, 2012. (24) Binet, C.; Mitov, M.; Mauzac, M. Switchable Broadband Light Reflection in PolymerStabilized Cholesteric Liquid Crystals. J. Appl. Phys. 2001, 90, 1730-1734.

(25) Baliyan, V. K.; Jeong, K.-U.; Kang, S.-W. Dichroic-Dye-Doped Short Pitch Cholesteric Liquid Crystals for the Application of Electrically Switchable Smart Windows. Dyes and Pigments 2019, 166, 403-409.

(26) Smalyukh, I. I. Thermal Management by Engineering the Alignment of Nanocellulose. Adv. Mater. 2020, 2001228.

(27) Parker, A. R. A Geological History of Reflecting Optics. J. R. Soc. Interface 2005, 2, 117.

(28) McNamara, E.; Briggs, D. E. G.; Orr, P. J.; Noh, H.; Cao, H. The Original Colours of Fossil Beetles. Proc. R. Soc. B 2012, 279, 1114-1121.

(29) Mitov, M. Cholesteric Liquid Crystals in Living Matter. Soft Matter 2017, 13, 4176-4209.

(30) Neville, A. C. Biology of the Arthropod Cuticle; Springer-Verlag: Berlin, Heildelberg, 1975. 
Accepted version in: ACS Applied Materials \& Interfaces 2021, 13, 30118-30126.

(31) Neville, A. C., Biology of fibrous composites; Cambridge University Press, 123-146, 1993.

(32) Bouligand, Y.; On a Twisted Fibrillary Arrangement Common to Several Biologic Structure. C. R. Acad. Sci. Hebd. Seances Acad. Sci. D. 1965, 261, 4864-4867.

(33) Lenau, T.; Barfoed, M.; Colours and Metallic Sheen in Beetle Shells-A Biomimetic Search for Material Structuring Principles Causing Light Interference. Adv. Eng. Mat. 2008, $10,299-314$.

(34) Wegst, U. G. K.; Bai, H.; Saiz, E.; Tomsia, A. P.; Ritchie, R. O. Bioinspired Structural Materials. Nat. Mater. 2015, 14, 23-36.

(35) Kolle, M.; Lee, S. Progress and Opportunities in Soft Photonics and Biologically Inspired Optics. Adv. Mater. 2018, 30, 1702669.

(36) Goldstein, H. Polarization Properties of Scarabaeidae. Appl. Optics 2006, 45, 7944-7950.

(37) Fernandez del Rio, L.; Arwin, H.; Järrendahl, K. Polarizing Properties and Structural Characteristics of the Cuticle of the Scarab Beetle Chrysina gloriosa. Thin Solid Films 2014, $571,410-415$.

(38) Agez, G.; Bayon, C.; Mitov, M. Multiwavelength Micromirrors in the Cuticle of Scarab Beetle Chrysina gloriosa. Acta Biomater. 2017, 48, 357-367.

(39) Hernández-Jiménez, M.; Azofeifa, D. E.; Libby, E.; Barboza-Aguilar, C.; Solís, Á.; ArceMarenco, L.; García-Aguilar, I.; Hernández, A.; Vargas, W. E. Qualitative Correlation between Structural Chirality through the Cuticle of Chrysina aurigans Scarabs and LeftHanded Circular Polarization of the Reflected Light. Opt. Mater. Express 2014, 4, 2632-2645. (40) Libby, E.; Azofeifa, D. E.; Hernández-Jiménez, M.; Barboza-Aguilar, C.; Solís, Á.; García-Aguilar, I.; Arce-Marenco, L.; Hernández, A.; Vargas, W. E. Light Reflection by the Cuticle of $C$. aurigans Scarabs: a Biological Broadband Reflector of Left Handed Circularly Polarized Light. J. Opt. 2014, 16, 082001. 
(41) Azofeifa, D. E.; Hernández-Jiménez, M.; Libby, E.; Solís, Á.; Barboza-Aguilar, C; Vargas, W. E. A Quantitative Assessment Approach of Feasible Optical Mechanisms contributing to Structural Color of Golden-Like Chrysina aurigans Scarab Beetles. J. Quant. Spectrosc. Rad. Transf. 2015, 160, 63-74.

(42) Vargas, W. E.; Hernandez-Jimenez, M.; Libby, E.; Azofeifa, D. E.; Solis, A.; BarbozaAguilar, C. Broadening of Effective Photonic Band Gaps in Biological Chiral Structures: From Intrinsic Narrow Band Gaps to Broad Band Reflection Spectra. Eur. Phys. Lett. 2015, $111,64001$.

(43) Scarangella, A.; Soldan, V; Mitov, M. Biomimetic Design of Iridescent Insect Cuticles with Tailored, Self-Organized Cholesteric Patterns. Nat. Commun. 2020, 11, 4108.

(44) Kreuzer, F. -H.; Häberle, N.; Leigeber, H.; Maurer, R.; Stohrer, J.; Weis, J. Cyclic Liquid Crystalline Siloxanes -Chemistry and Applications, 566-586, in Organosilicon Chemistry III; Auner, N., J. Weiss, J., Eds.; Wiley-VCH: Weinheim, Germany, 1997.

(45) Mitov, M.; Boudet, A.; Sopena, P.; Sixou, P. Morphological Study of a Chiral Polymer Network in a Nematic Liquid Crystal from a Concentration Gradient. Liq. Cryst. 1997, 23, 903-910.

(46) St. John, W. D.; Fritz, W. J.; Lu, Z. J.; Yang, D.-K. Bragg. Reflection from Cholesteric Liquid-Crystals. Phys. Rev. E 1995, 51, 1191-1198.

(47) Friedel, G. Sur les Corps Cholestériques, C. R. Acad. Sci. Fr. 1923, 176, 475-478.

(48) Kozawaguchi, H.; Wada, M. Dependence of Helical Pitch on Composition in Mixtures of Nematic and Cholesteric Liquid-Crystals, Mol. Cryst. Liq. Cryst. 1978, 44, 97-112.

(49) Pierron, J.; Boudet, A.; Sopena, P.; Mitov M.; Sixou, P. Cholesteric Textures observed by Transmission Electron Microscopy in Diffraction Contrast, Liq. Cryst. 1995, 19, 257-267. 
(50) Boudet, A.; Mitov, M.; Bourgerette, C.; Ondarçuhu, T.; Coratger, R. Glassy Cholesteric Structure: Thickness Variation Induced by Electron Radiation in Transmission Electron Microscopy Investigated by Atomic Force Microscopy. Ultramicroscopy 2001, 88, 219-229. (51) Brehm, V. M.; Finkelmann, H; Stegemeyer, H. Orientierung Cholesterischer Mesophasen an mit Lecithin Behandelten Oberflachen, Ber. Bunsenges. Phys. Chem., Phys. Chem. 1974, $78,883-886$.

(52) Oswald, P.; Baudry, J.; Pirkl, S. Static and Dynamic Properties of Cholesteric Fingers in Electric Field, Physics Reports 2000, 337, 67-96.

(53) Makow, D. M.; Leroy-Sanders, C. Additive Colour Properties and Colour Gamut of Cholesteric Liquid Crystals. Nature 1978, 276, 48-50.

(54) Kim, D. Y.; Lee, K. M.; White, T. J.; Jeong, K. U. Cholesteric Liquid Crystal Paints: in situ Photopolymerization of Helicoidally Stacked Multilayer Nanostructures for Flexible Broadband Mirrors. NPG Asia Materials 2018, 10, 1061-1068.

(55) Mitov, M.; Boudet, A.; Sopena, P. From Selective to Wide-Band Light Reflection: a Simple Thermal Diffusion in a Glassy Cholesteric Liquid Crystal. Eur. Phys. J. B 1999, 8, $327-330$.

(56) Xiao, J.; Cao, H.; He, W.; Ma, Z.; Geng, J.; Wang, L.; Wang, G.; Yang, H. Wide-Band Reflective Polarizers from Cholesteric Liquid Crystals with Stable Optical Properties. J. Appl. Polym. Sci. 2007, 105, 2973-2977.

(57) Wang, S.; Liu, X.; Yang, M.; Zhang, Y.; Xiang, K.; Tang, R. Review of Time Temperature Indicators as Quality Monitors in Food Packaging. Packag. Technol. Sci. 2015, $28,839-867$.

(58) Sage, I. Thermochromic Liquid Crystals. Liq. Cryst. 2011, 38, 1551-1561. 
(59) Hao, L. T.; Lee, M.; Jeon, H.; Koo, J. M.; Hwang, S. Y.; Oh, D. X.; Park, J. TamperProof Time-Temperature Indicator for Inspecting Ultracold Supply Chain. ACS Omega 2021, 6, 8598-8604.

(60) Yang. K. H. Measurements of Empty Cell Gap for Liquid-Crystal Displays using Interferometric Methods. J. Appl. Phys. 1988, 64, 4780-4781.

(61) Weaver, J. C.; Milliron, G. W.; Miserez, A.; Evans-Lutterodt, K.; Herrera, S.; Gallana, I.; Mershon, W. J.; Swanson, B.; Zavattieri, P.; DiMasi, E.; Kisailus. D. The Stomatopod Dactyl Club: A Formidable Damage-Tolerant Biological Hammer. Science 2012, 336, 1275-1280.

(62) Mitov, M.; Soldan, V.; Balor, S. Observation of an Anisotropic Texture inside the Wax Layer of Insect. Arthropod Struct. \& Development 2018, 47, 622-626. 


\title{
Supporting Information
}

\author{
Bioinspired, Cholesteric Liquid Crystal Reflectors with \\ Time-Controlled, Coexisting Chiral and Achiral Structures
}

Cécilia Boyon, ${ }^{1}$ Vanessa Soldan, ${ }^{2}$ and Michel Mitov ${ }^{*}, 1$

${ }^{1}$ Centre d'Elaboration de Matériaux et d'Etudes Structurales, CEMES, CNRS, Toulouse, France.

${ }^{2}$ Centre de Biologie Intégrative, CBI, Microscopie Electronique Intégrative, METi, CNRS, University of Toulouse, France.

*Corresponding Author. E-mail: mitov@ cemes.fr 


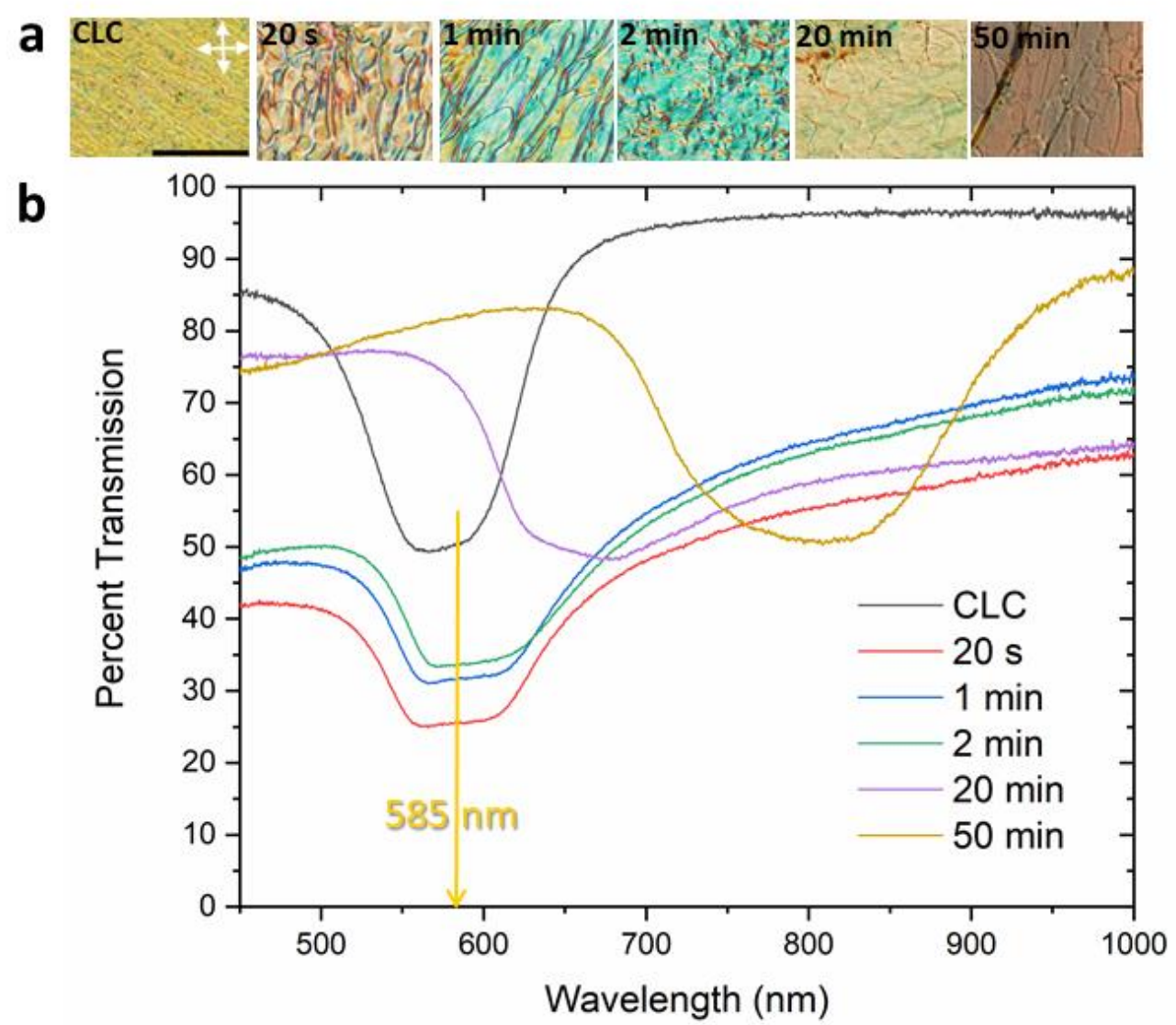

Figure S1. Transmission properties of the cells for different annealing times and at normal incidence. (a) Optical textures (transmission mode, crossed polarizers; the white arrows indicate the orientation of the crossed polarizers). Scale bar $=50 \mu \mathrm{m}$. (b) Transmission spectra. For the $20 \mathrm{~s}, 1 \mathrm{~min}$ and 2 min samples, the transmittance of the whole signal, inside and outside of the Bragg band, is low with regard to that of the CLC film; the latter exhibits a high transmittance from $85 \%$ at $450 \mathrm{~nm}$ to $95 \%$ at $1000 \mathrm{~nm}$. These low diffusion times do not allow the films to reach a clear-cut planar texture after the two layers are put into contact: in (a), peculiar oily streaks in the textures related to the $20 \mathrm{~s}, 1 \mathrm{~min}$ and $2 \mathrm{~min}$ samples are visible, which are absent in the texture related to the CLC film. As a consequence, diffuse reflection occurs instead of specular reflection. This observation is congruent with that of the fingerprint textures of cross-sections shown in Figures 6a to c: the stripes are slightly wavy in the contact region between the two layers corresponding to a frustrated helical structure; consequently, the 
direction of light propagating through this region is not kept perpendicular to the film surfaces. A better planar texture is obtained at $20 \mathrm{~min}$ : the transmittance level is higher, and in (a), the texture shows oily streaks thinner than those seen at $20 \mathrm{~s}, 1 \mathrm{~min}$ and $2 \mathrm{~min}$; their density is also lower. A planar texture with a transmittance level closer to that of the CLC film is shown in the 50-min film.
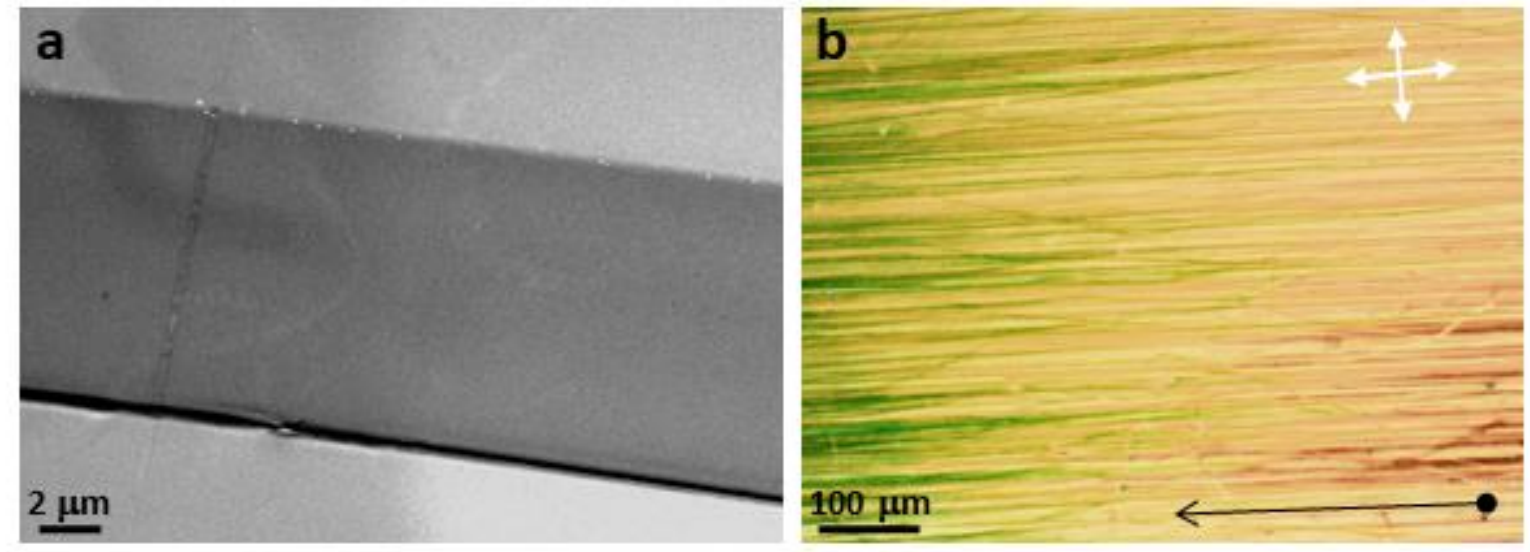

Figure S2. Textures of the NLC sample. (a) TEM transverse view of a 10- $\mu$ m-thick polymerized NLC sample. No patterns or defects are visible. This is probably the consequence of the clear-cut planar alignment in the whole volume of the thin NLC film. (b) Optical micrograph (transmission mode, crossed polarizers; the white arrows indicate the orientation of the crossed polarizers). The black arrow indicates the rubbing direction of the alignment layers. 


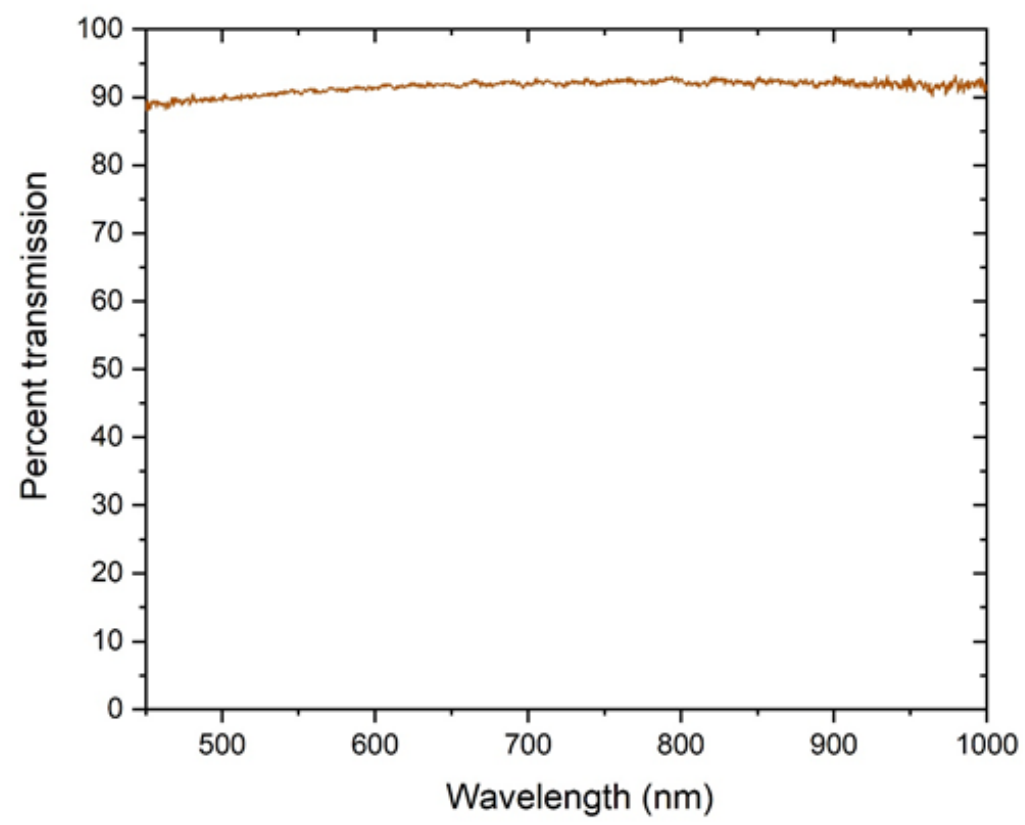

Figure S3. Typical transmission spectrum of an individual NLC film.

\begin{tabular}{|c|c|c|c|c|c|c|c|}
\cline { 2 - 7 } \multicolumn{1}{c|}{} & CLC & NLC & $20 ~ s$ & 1 min & $\mathbf{2} \mathbf{~ m i n}$ & $\mathbf{2 0} \mathbf{~ m i n}$ & $\mathbf{5 0} \mathbf{~ m i n}$ \\
\hline $\begin{array}{c}\text { Thickness } \\
(\mu \mathrm{m})\end{array}$ & $14.0 \pm 1.0$ & $7.5 \pm 0.5$ & $18.5 \pm 0.5$ & $17.5 \pm 0.5$ & $18.0 \pm 0.5$ & $22.0 \pm 0.5$ & $13.0 \pm 0.5$ \\
\hline
\end{tabular}

Table S1. Thickness of individual CLC and NLC films - as calculated from the interference method (see the Experimental section), and samples after polymerization (as calculated from TEM transverse images). 